\title{
Immunoglobulin D Measurement
}

National Cancer Institute

\section{Source}

National Cancer Institute. Immunoglobulin D Measurement. NCI Thesaurus. Code C98745.

The determination of the amount of immunoglobulin $D$ present in a sample. 